\title{
Daily Estimate of Pure Water in a Desalination Unit by Solar Membrane Distillation
}

Mandiang $Y^{*}$, Sene M, Thiam A and Azilinon D

ESP/UCAD BP 64445 Poste UCAD - Dakar Fann, Senegal

\begin{abstract}
A membrane distillation process using solar energy has been studied. This system has been modelled to provide approximations of the flow of distillate, the thermal effectiveness and the quantities of heat exchanged by conduction and evaporation during the production process of water. Then, simulations have been carried out using MATLAB to highlight the transfers of mass and energy in a dynamic regime under the effect of variable solar radiation and to illustrate the temporal evolution of the parameters related to the operation of the membrane. So, to estimate the production of water, a polynomial approximation was used.
\end{abstract}

Keywords: Membrane; AGMD; Solar-power; Daily; Water production

\section{List of Symbols}

Cp: $\quad$ Specific heat $(\mathrm{kJ} / \mathrm{kg} . \mathrm{K})$

Cs: Mole fraction of $\mathrm{NaCl}$

Ds; Diffusion coefficient of the $\mathrm{NaCl},\left(\mathrm{m}^{2} / \mathrm{s}\right)$ $\left(\mathrm{m}^{2} / \mathrm{s}\right)$

Dv/a: Diffusion coefficient of the vapour in the vapour/air mixture,

Jv: Local permeate flux at the hot side of membrane, in vapour phase $\left(\mathrm{kg} / \mathrm{m}^{2} . \mathrm{s}\right)$

k: Thermal conductivity (W/m.K)

K: Permeability of the membrane $(\mathrm{s} / \mathrm{m})$

$\mathrm{H}$ : Membrane length (m)

Mv: Molar mass $(\mathrm{kg} / \mathrm{mol})$

Pm: Average pressure partial of the air $(\mathrm{Pa})$

PT: Total pressure (air + vapor) $(\mathrm{Pa})$

r: $\quad$ Sze $(\mathrm{m})$

rp: Membrane pore size $(\mathrm{m})$

R: Universal gas constant (J/mol.K)

$\mathrm{r}_{1}$ : Interior radius of the membrane $(\mathrm{m})$

$\mathrm{r}_{2}$ : Exterior radius of membrane $(\mathrm{m})$

$\mathrm{T}$ : Inlet temperature of hot solution $\left({ }^{\circ} \mathrm{C}\right)$

Tm: Average temperature of the membrane $\left({ }^{\circ} \mathrm{C}\right)$

Ve: Velocity at the inlet of the hot channel $(\mathrm{m} / \mathrm{s})$

Vr: Radial velocity $(\mathrm{m} / \mathrm{s})$

Vz: Axial velocity (m/s)

Greek:

$\rho$ : Density $\left(\mathrm{kg} / \mathrm{m}^{3}\right)$

$\varepsilon$ : Porosity of membrane;

$\tau$ : Tortuosity $\delta \mathrm{m}$ : Thickness or width $=\mathrm{R}_{2} \ln \left(\mathrm{R}_{2} / \mathrm{R}_{1}\right)$

$\delta \mathrm{g}$ : Thickness or air (m)

$\delta f$ : Thickness of film of condensation (m)

$\mu$ : Dynamic viscosity $(\mathrm{kg} / \mathrm{m} . \mathrm{s})$

Subscripts

c: Condensation

co: Conduction

e: Inlet of the channel

f: Condensate film

fg: Changement de phase liquide-vapeur

g: Couche d'air

hm: Hot liquid/membrane interface

m: Membrane

mg: Membrane/air gap interface

p: Pores

s: Saline

v/a: Vapour/air

\section{Introduction}

In many countries, particulaly in Senegal at the delta of Saloum river, water is available but is saline or has a high composition of other chemicals, particularly those that are fluorinated. This water is often dangerous for domestic and agricultural use. Desalination is essential to resolve these problems. Several techniques can be used to desalinate

*Corresponding author: Mandiang Y, ESP/UCAD BP 64445 Poste UCAD Dakar Fann, Senegal, Tel: 2217753259 72; E-mail: youssouf.mandiang@yahoo.com

Received April 25, 2015; Accepted May 15, 2015; Published May 24, 2015

Citation: Mandiang Y, Sene M, Thiam A, Azilinon D (2015) Daily Estimate of Pure Water in a Desalination Unit by Solar Membrane Distillation. J Material Sci Eng 4: 170. doi:10.4172/2169-0022.1000170

Copyright: (c) 2015 Mandiang Y, et al. This is an open-access article distributed under the terms of the Creative Commons Attribution License, which permits unrestricted use, distribution, and reproduction in any medium, provided the original author and source are credited. 
brackish water, but it is significant that the delta of Saloum river is characterized by significant solar irradiation throughout the year [1]. The installation of processes based on phase changes such as Multi Effect Distillation (MED), Vapour Compression (VC), Mechanical Vapour Compression (MVC) and Multi Stage Flash (MSF) pose a local problem because of the resulting stripping of the contaminants. Thus, membrane processes such as Direct Contact Membrane Distillation DCMD, Air Gap Membrane Distillation (AGMD), Sweeping Gas Membrane Distillation (SGMD) and Vacuum Membrane Distillation (VMD) that use solar energy are more favourable.

Membrane processes are often underutilized or poorly used [2]. Many advanced earlier work has been done and experimental results to enhance these processes were reported [1]. Membrane techniques, depending on the amount of the available energy, such as thermal or reverse osmosis, distillation or flash successive expansions arrive daily to produce large quantities of fresh water. The global production, for these processes, was estimated to about $25 \% 10^{6} \mathrm{~m}^{3} / \mathrm{d}[3,4]$. However, the problem of reducing the energy consumption of desalination processes is becoming obvious more and more.

The demand for water is estimated to be, on average, 40 litres per person per day, and this production can be achieved by AGMD, a desalination technique considered promising due to its advantages, including low temperature $\left(30^{\circ} \mathrm{C}\right.$ to $\left.90^{\circ} \mathrm{C}\right)$, and ability to use solar energy[5].

A recent work on the state of the art of membrane distillation (MD) and its various applications was presented by El Bourawi [6]. The author showed that membrane distillation is an attractive process because it consumes little energy, making it very favourable for use in developing countries.

A very thorough and detailed study of AGMD was published by Aklaibi and Lior [7]. Its principal advantage compared to DCMD is the reduction of heat losses through the membrane. Their results were compared with previously published experimental results and provided information on the phenomena of transfer. Their principal conclusions are as follows:

- The diameter of the pores has a notable effect on the performance of the process;

- The inlet temperature of the hot fluid has an influence on the flow of the permeate and also increases the thermal effectiveness, whereas an increase in the temperature of coolant has a smaller effect on the growth of the flow rate and reduces the effectiveness slightly;

- The concentration of the saline solution at the entry has a negligible influence on the flow of the permeate and the thermal effectiveness;

- The speeds of the entry of the hot and cold solutions do not have a significant effect;

- The reduction of the thermal conductivity of the membrane improves the thermal effectiveness of the process and, more remarkably, increases the flow of the drinking water.

Other researchers including Meindersma, Guijt, Payo, Chouikh work on AGMD, but none of them used solar as the energy source [8$11]$.

More recently Mandiang have studied three different types of mass transfer modes through the membrane and compared with one another
[12]. The results reported by these authors showed that the molecular flow is dominant, but a series combination of the three transfer modes is most appropriate for a better estimation of the vapour stream generated.

However, no study evaluated the daily production of fresh water and the speed profiles of the vapour in the membrane, so the purpose of the present paper is to build upon the work of the above mentioned authors by studying the daily production.

\section{Description of the Set-up}

Our work refers to a model of AGMD in which the flow of the fluids is counter-current. A diagram of this desalination technique is shown in Figure 1. The saline feed water is heated in a unit comprising a solar collector and heat exchanger. This heated water passes through a pump whose flow is controlled and enters a tubular space composed of a hydrophobic microporous membrane through which the steam passes, capturing the nonevapourable portion of the water.

The difference in temperature between the interior flow of the tubular membrane and the external layer of air creates a difference in the pressure, which drives the vapour through the pores of the membrane. The vapour condenses on a cooled wall, and pure water is obtained at the button. Cooling is done by external streaming on a tube, and this water is recycled.

\section{Mechanisms of Mass Transfer}

This module for the production of drinking water uses the principle shown in Figure 2. It is composed of two concentric tubes (zone of study). The interior tube is a hydrophobic membrane in which circulates a hot saline solution, and the external tube is a cold wall of condensation. Inside the wall of condensation, pure water oozes, while on the outside, cool water streams.

The three types of mechanisms shown in Figure 3, incorporated in KMPT (Knudsen diffusion-Molecular diffusion-Poiseuille flow Transition) are:

* Knudsen diffusion (based on collisions between molecules and the-wall);

* Molecular diffusion (based on collision between molecules), and

* Viscous diffusion (based on both types of collisions) [7].

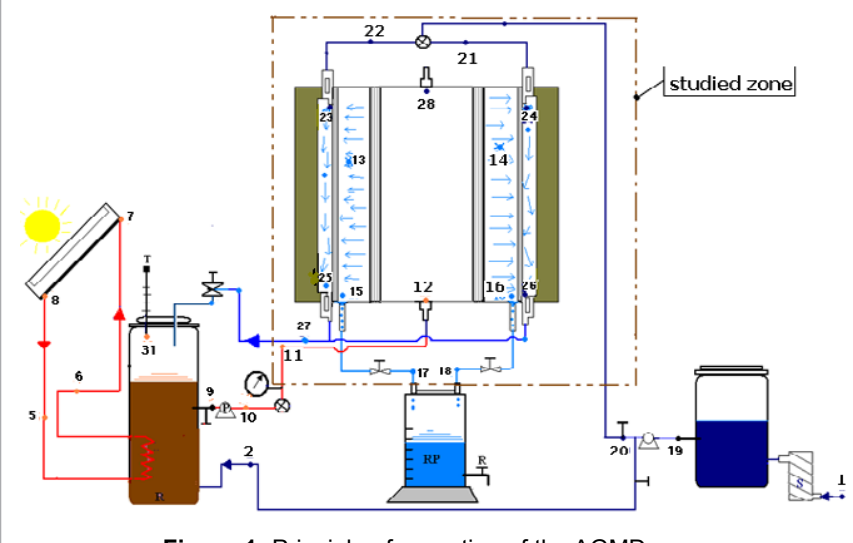

Figure 1: Principle of operation of the AGMD. 


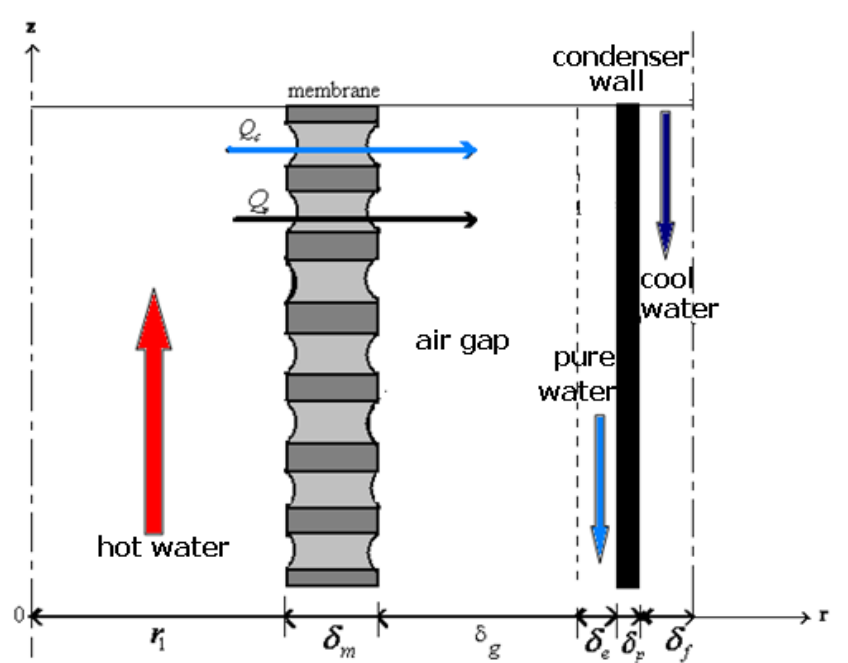

Figure 2: Model AGMD with interfaces of the flows.

Legend- $r_{1}$ : Inner radius of the membrane; $\delta_{m}$ : thickness of the membrane; $\delta_{g}$ : thickness of air layer; $\delta_{e}$ : thickness of pure water; $\delta p$ : wall thickness of condensation. $\delta_{f}$ : thickness of cold water runoff film.

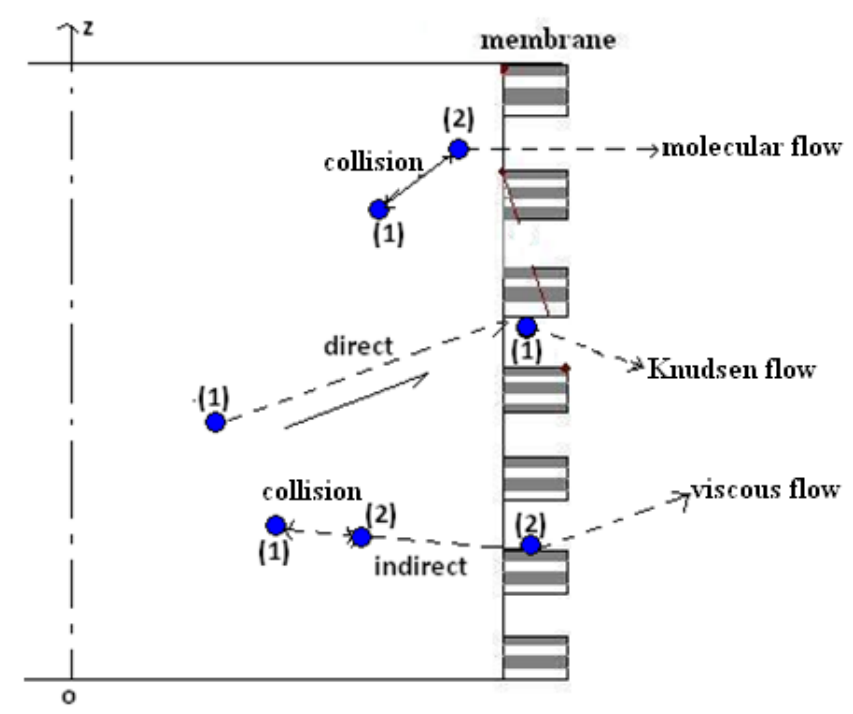

Figure 3: Three modes of diffusions through the membrane.

\section{Mathematical Modelling}

The establishment of mathematical models of heat transfers in a porous environment is inspired directly by the methods that are traditionally used in the mechanics of continuous mediums to determine local expressions of the laws of conservation. The assumptions include:

- Incompressible Newtonian fluid;

- Nonviscous fluid;

- Permanent laminar mode;

- Axisymetric flow;

- Minimal loss of heat in the module;

- Nonreactive membrane;
- Uniform temperature of condensation;

- Profile speeds is parabolic along the $\mathrm{z}$-axis, and

- Isothermal flow.

\section{Flow in the membrane}

The equations governing the flow and the transfers of heat and mass in the hot feed water are:

- Conservation of mass

$$
\frac{\partial V_{z}}{\partial z}+\frac{1}{r} \frac{\partial}{\partial r}\left(r V_{r}\right)=0
$$

- Momentum in the directions of $\mathrm{r}$ and $\mathrm{z}$

$$
\begin{aligned}
& \rho\left(V_{r} \frac{\partial V_{r}}{\partial r}+V_{z} \frac{\partial V_{r}}{\partial z}\right)=-\frac{\partial P}{\partial r}+\mu\left[\frac{\partial}{\partial r}\left(\frac{1}{r} \frac{\partial}{\partial r}\left(r V_{r}\right)\right)+\frac{\partial^{2} V_{r}}{\partial z^{2}}\right] \\
& \rho\left(V_{r} \frac{\partial V_{r}}{\partial r}+V_{z} \frac{\partial V_{r}}{\partial z}\right)=-\frac{\partial P}{\partial z}-\rho g+\mu\left[\frac{1}{r} \frac{\partial}{\partial r}\left(r V_{z}\right)+\frac{\partial^{2} V_{r}}{\partial z^{2}}\right] \\
& \text { - Energy } \\
& V_{r} \frac{\partial T}{\partial r}+V_{z} \frac{\partial T}{\partial z}=D_{f}\left[\frac{1}{r} \frac{\partial}{\partial r}\left(r \frac{\partial T}{\partial r}\right)+\frac{\partial^{2} T}{\partial z^{2}}\right]
\end{aligned}
$$

- Species

$$
\left(V_{r} \frac{\partial C_{s}}{\partial r}+V_{z} \frac{\partial C_{s}}{\partial z}\right)=D_{s}\left[\frac{1}{r} \frac{\partial}{\partial r}\left(r \frac{\partial C_{s}}{\partial r}\right)+\frac{\partial^{2} C_{s}}{\partial z^{2}}\right]
$$

All these equations are controlled using initial and boundary conditions

\section{Modes of flow}

Knudsen diffusion: In the theory of Knudsen diffusion, the transfer of gas is controlled by the successive collisions of the particles with a wall in the way of diffusion

$$
J_{K}=\frac{2}{3} \frac{\varepsilon}{\tau} r_{p} \sqrt{\frac{8 M_{v}}{\pi R \bar{T}_{m}}}\left(\frac{p_{h m}-p_{m g}}{\delta_{m}}\right)
$$

Molecular diffusion: The relation of diffusive flow through a membrane is obtained by:

$$
J_{M, S}=\frac{\varepsilon \cdot P D_{v / a} M_{v}}{\tau \delta_{m} R \bar{T}_{m}}\left(\frac{p_{h m}-p_{m g}}{p_{a}}\right)
$$

The equation showing the influence of the salinity and the temperature on the saturated vapour pressure is that of Raoul [7]:

$$
p_{h m}=(1-S) p_{v}
$$

where $S$ is the salinity .

Viscous diffusion or law of one-tenth of poise: This model is based on the viscous flow of the vapour and is given by:

$$
J_{p}=\frac{1}{8 \mu_{g}} \frac{r_{p}^{2} \varepsilon}{\tau} \frac{M_{v}}{R \bar{T}_{m}} \frac{\Delta p_{v}}{\delta_{m}}
$$

The partial pressure of the saturated vapour can be calculated according to Alkaibi [13] and Lior [14] by the following equation: 


$$
\ln p_{v}=23,328-\frac{3841}{T-45}
$$

where $\mathrm{T}$ is the temperature of the solution

\section{Results and Discussion}

Simulations were carried out with the following input data: $\mathrm{k}_{\mathrm{m}}=0.05 \mathrm{~W} \cdot \mathrm{m}^{-1} \mathrm{~K}^{-1} ; \delta_{\mathrm{m}}=4.10^{-4} \mathrm{~m} ; \mathrm{Tc}=20^{\circ} \mathrm{C} ; \varepsilon=75 \%$. Figure 4 exhibits the changes in the dynamic viscosity as a function of the water evaporation temperature. The shape of this curve suggests a low variation in this parameter in the investigated temperature range, so that for mass transfer simulation, the dynamic viscosity of the vapour can be estimated to be $10^{-5} \mathrm{~kg} / \mathrm{m} . \mathrm{s}$.

Figure 5 shows the evolution of the excisable differential pressure across the membrane that enables it to get wet (contact angle higher than $90^{\circ}$ ). This figure illustrates the hydrophobicity of each membrane type. We note that high values of the surface tension as well as small pore

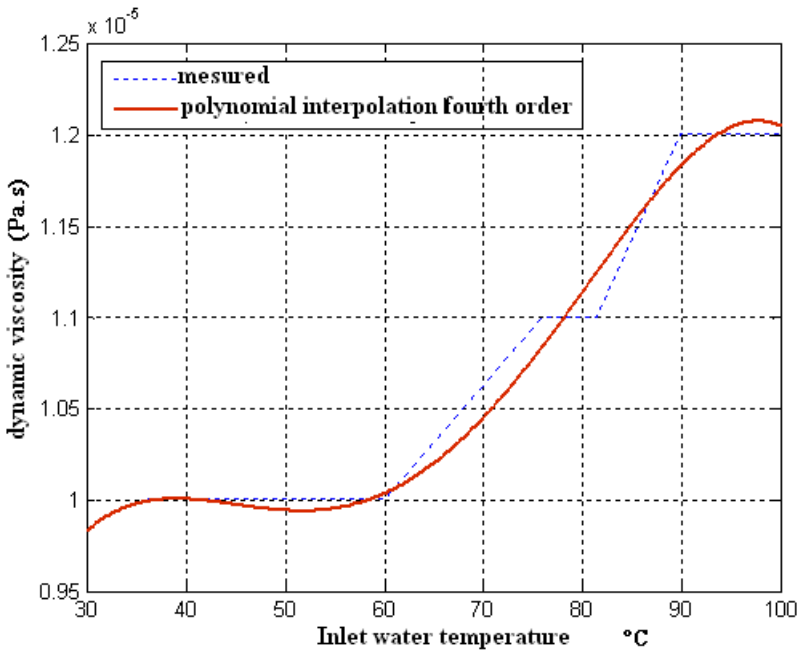

Figure 4: Evolution of dynamic viscosity.

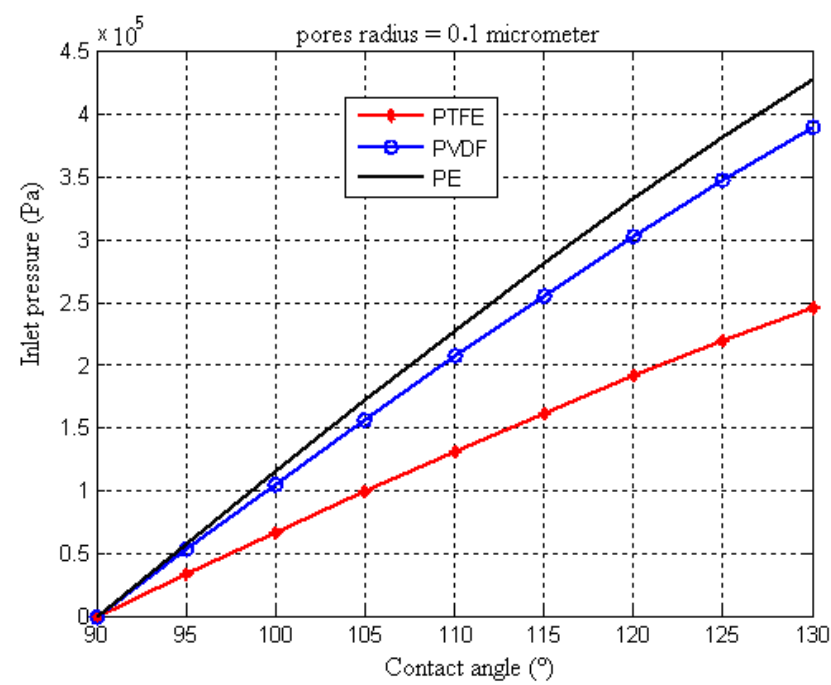

Figure 5: Inlet pressure as function of the contact angle for three types of membrane.

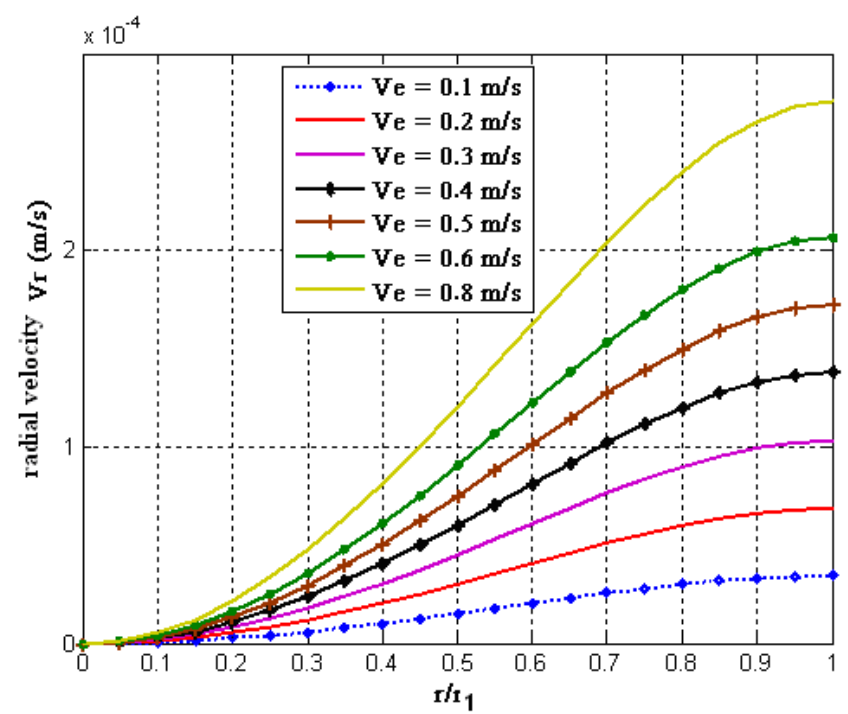

Figure 6: Radial velocity at the entry depending on the membrane radius.

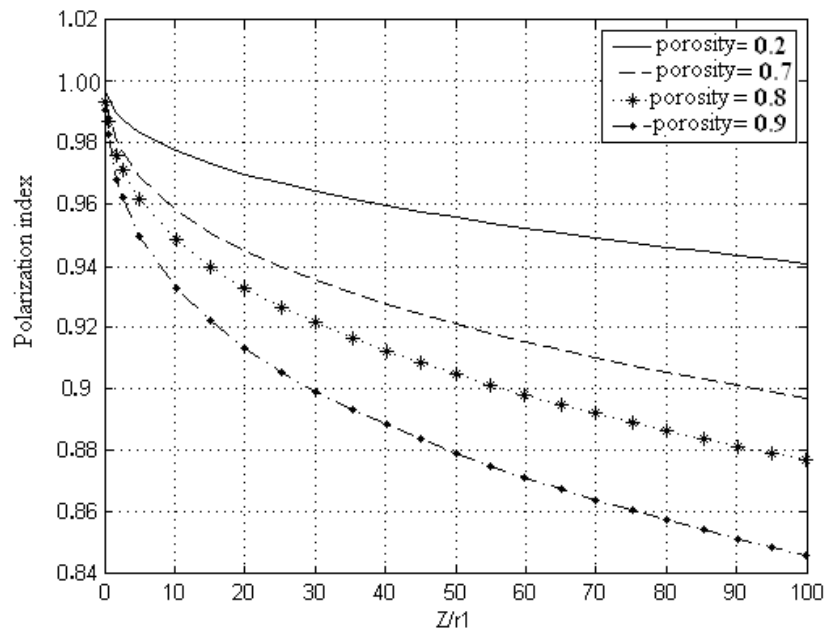

Figure 7: Coefficient of polarization of the temperature.

sizes induce rather significant pressures differences. For this reason, the PTFE membrane is often used because it is more hydrophobic than the others (e.g., PVDF, PE). Figure 6 shows the evolution of the vapour radial velocity at the inlet of the membrane ( $r_{1}$ is the inner radius) and at level $\mathrm{z}=0 \mathrm{~m}$. This velocity was found to increase along the radius for given inlet velocities of the hot solution - from $0.1 \mathrm{~m} / \mathrm{s}$ to $0.8 \mathrm{~m} / \mathrm{s}$ and was shown to be higher at the wall of the membrane, which could enhance the water production.

Figure 7 illustrates changes in the polarization coefficient of the temperature along the axial direction $(\mathrm{z})$ as well as the influence of the membrane porosity. This coefficient was found to decrease from the inlet to the out-let of the tube as well as with the increase in membrane porosity.

The polarization temperature causes a significant loss of the driving force for transport $\left(T_{h m}-T_{g f}\right)$ compared to the imposed force $\left(T_{f}-T_{c}\right)$. This force is also reduced by the pressure drop of the water vapour due to the presence of salt on the supply side. A validation of the theoretical 
model was performed by comparing our results with the experimental results of Banat on a membrane [15]. The results reported by Baoan and Ding indicate that a value of the polarization coefficient of approximately 1.0, is acceptable and Figure 7 exhibits good agreement with these earlier results $[16,17]$.

The inlet temperature effect on the transmembrane flow compared with the experimental work of Banat is illustrated Figure 8, and our theoretical model is found to be in good agreement. The mass transfer for three flows depending on the inlet temperature of the feed water is exhibited in Figure 9. Molecular flow was found to have the superior production in the investigated temperature range, and the values are in good agreement with the experimental values reported by Banat.

Molecular flux production for various membrane porosities has been investigated. Increasing porosity results in an increase in the flow rate Figure 10, confirming that the membrane porosity must be higher than $70 \%$. Figure 11 shows the temporal variation of the feed solution temperature during a hot typical workday, taking the shape of a bell curve when using a solar power system. The highest temperature was observed at 14:00 in the investigated areas. This time corresponds to the sunshine hour during the reference sunny day, at which the sunlight rate is found to be highest in the study area. This observation was confirmed by the result plot in Figures 12 and 13, where the daily

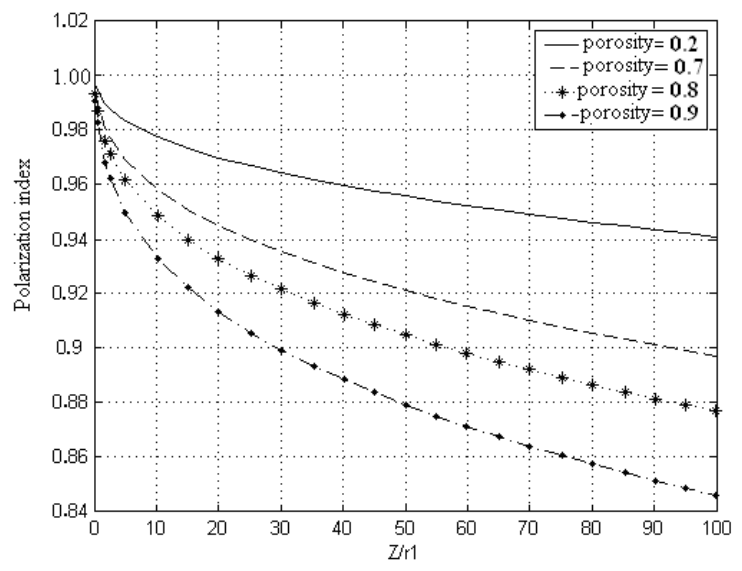

Figure 8: Effect of the inlet temperature on the transmembrane flow compared with experimental work of Banat.

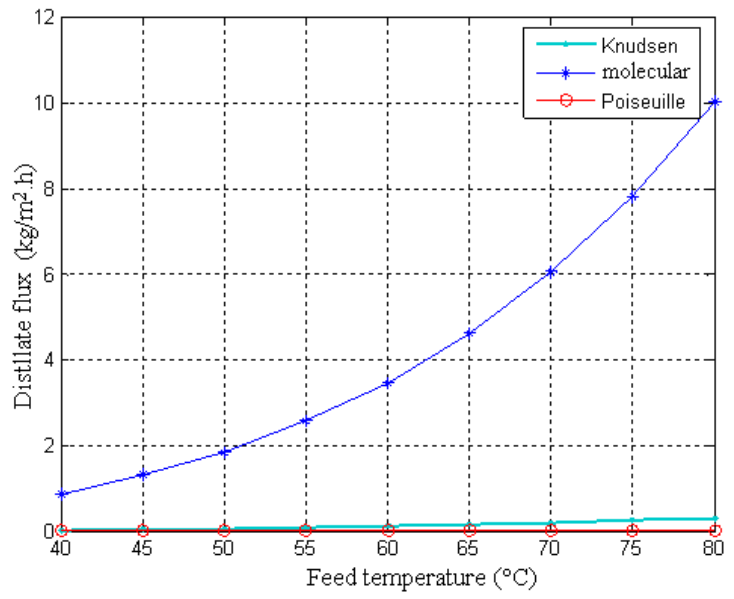

Figure 9: Mass transfer of three flows according to the inlet temperature.

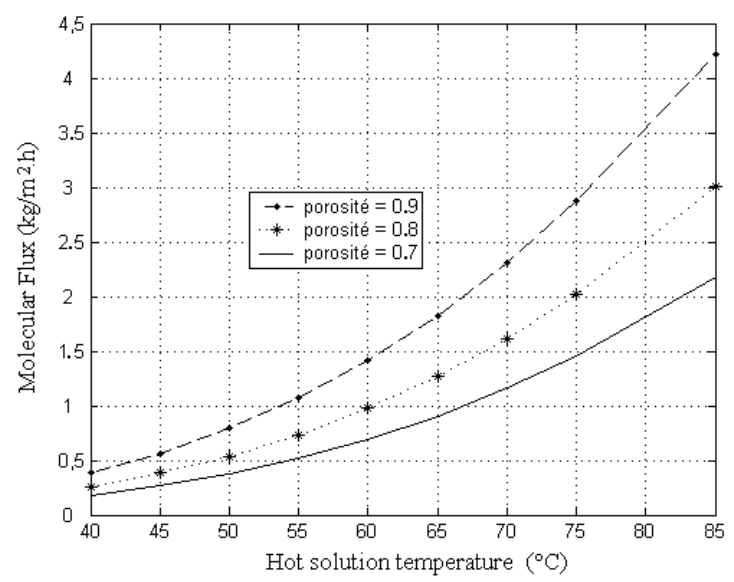

Figure 10: Mass transfer according to the solution temperaturefor various membrane porosities

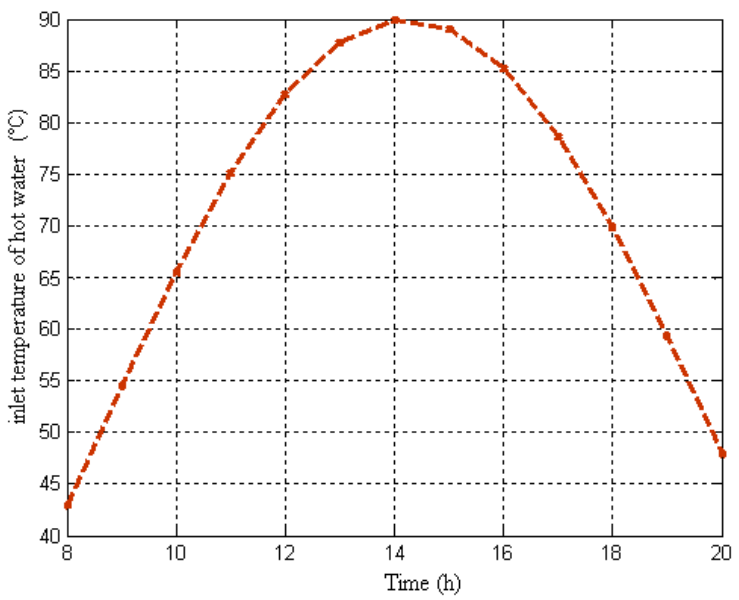

Figure 11: Changes in the temperature of the hot solution during a typical workday.

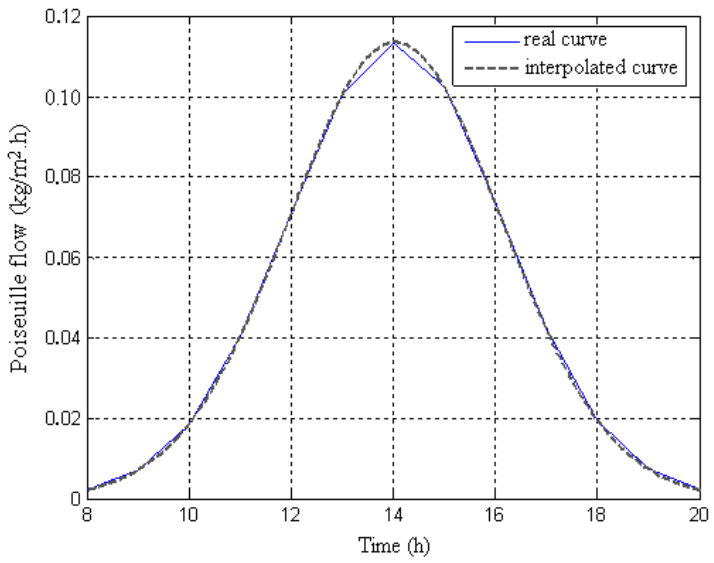

Figure 12: Variation of daily flux for Poiseuille's flow.

flux variations for Poiseuille's flow and for the distillate are shown, respectively. Figure 14 illustrates the influence of the temperature of the hot solution on the freshwater production for given input data (for 


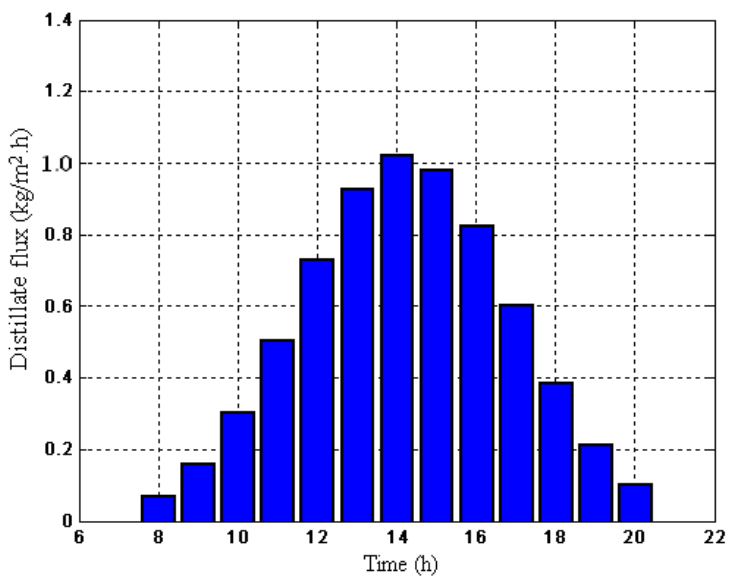

Figure 13: Evolution of the daily flux for molecular diffusion.

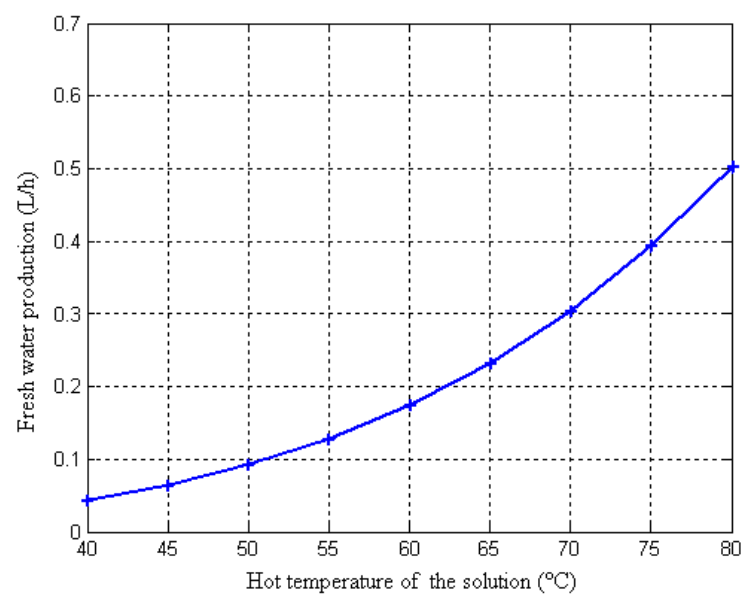

Figure 14: Production of pure water

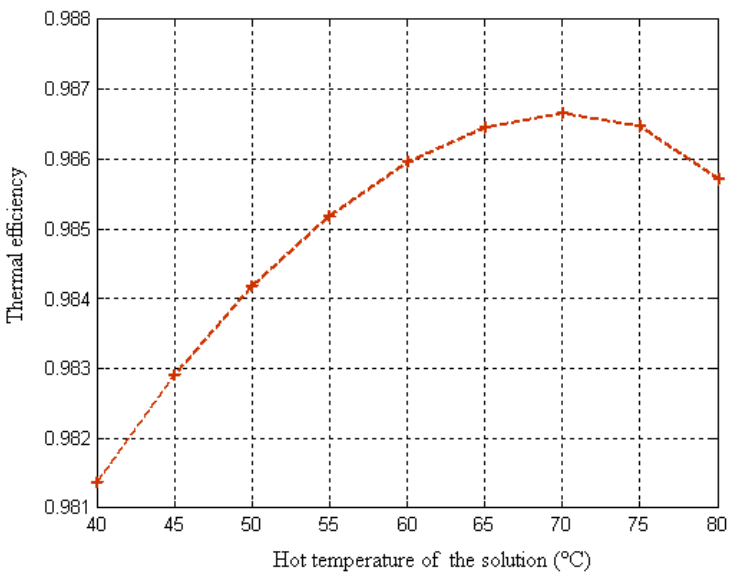

Figure 15: Evolution of the thermal effectiveness according to the temperature of the hot solution.

$H_{\mathrm{m}}=0.2 \mathrm{~m}$ and $r_{1}=2 \mathrm{~mm}$ ). It can be easily observed that the fresh water production increases with the increasing hot water temperature, which is not a surprise. The efficiency of the membrane process has been

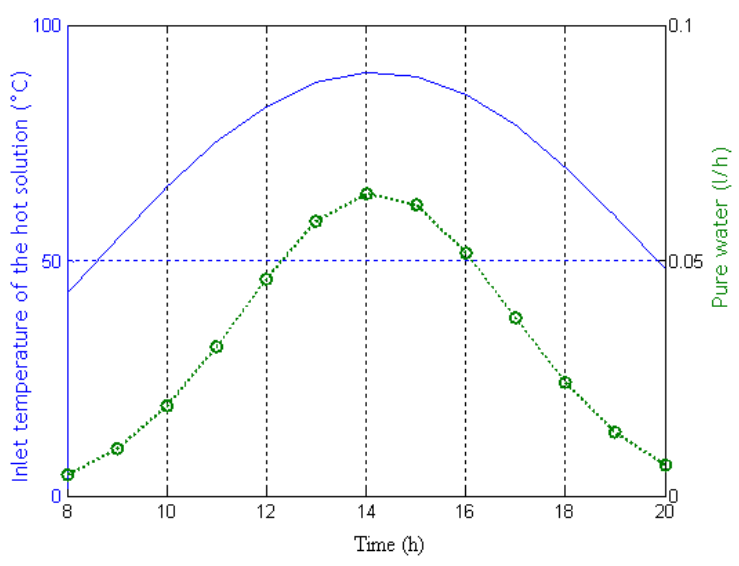

Figure 16: Changes in the temperature of the hot solution and the daily production.

assessed Figure 15 depending on the temperature of the hot salt water, and the best value was observed for $70^{\circ} \mathrm{C}$.

Figure 16 exhibits the daily fresh water production changes with the temperature of the hot solution for a typical work-day. On a sunny day, the highest temperatures and water production generated by the

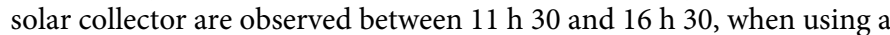
solar- power system in the areas investigated.

\section{Conclusions}

The present work provides a theoretical formulation and a numerical analysis of the mechanisms of the transport of mass, energy, and momentum in a membrane distillation unit with a layer of air, which is used for the desalination of sea water.

A validation this model was carried out by comparing these results with the experimental results previously reported on a PTFE membrane. The polarization of temperature generates significant loss in the driving force compared to the imposed force. This force was shown to be also reduced by the decrease in the pressure with the inlet solution due to the presence of salt.

The quantity of pure water produced was determined using AGMD through the membrane, by fixing the height of the vapour column at various points on the axis of the membrane. This process of desalination by membrane distillation uses solar power as an energy source, making it of interest for certain arid areas. The production costs are lowered because of the reduction of the quantity of chemicals used for the pretreatment of the water, preventing the precipitation of salt on the components of the installation. The study in the dynamic regime enables observing changes in the daily production of freshwater.

However, the analysis of these results has identified the limits of the hydrophobic nature of the membrane. Later studies would contribute to an improvement at the same time of the solar-power system and the mathematical model.

\section{References}

1. Sene M (2010) Transferts De Chaleur Et De Masse Dans Des Procédés De Dessalement Par Distillation Membranaire, Type Agmd. Valorisation Des Ressources En Eau Dans Le Delta Du Saloum, Dakar.

2. Mathioulakis E, Belessiotis V, Delyannis E (2007) Desalination By Using Alternative Energy: Review and State-of-The-Art National Center For Scientific Research (Ncsr) Demokritos, Aghia Paraskevi, 153-10. 
Citation: Mandiang Y, Sene M, Thiam A, Azilinon D (2015) Daily Estimate of Pure Water in a Desalination Unit by Solar Membrane Distillation. J Material Sci Eng 4: 170. doi:10.4172/2169-0022.1000170

Page 7 of 7

3. Akili DK, Ibrahim KK, Jong-Mihn W (2008) Advances In Seawater Desalination Technologies. Desalination 221: 47-69.

4. Loussif N, Orfi J, Sene M, Sow O, Mare T (2009) Transferts Couplés De Chaleur Et De Masse Dans Une Unité De Dessalement Par Distillation Membranaire Université De Monastir, Tunisie, King Saud University, Riyadh, Ksa, Université Cheikh Anta Diop De Dakar, Sénégal, lut St Malo, France.

5. Alklaibi AM (2008) The Potential of Membrane Distillation As A Stand-Alone Desalination Process. Desalination 223: 375-385.

6. El-Bourawi MS, Ding Z, Ma R, Khayet M (2006) A Framework For Better Understanding Membrane Distillation Separation Process. Journal of Membrane Science 285: 4-29.

7. Alkaibi AM, Lior N (2005) Transport Analysis Of Air Gap Membrane Distillation. Journal of Membrane Science 255: 239-253.

8. Meindersma GW, Guijit CM, De Haan AB (2006) Desalination And Water Recycle By Air Gap Membrane Distillation. Desalination 187: 291-301.

9. Guijt CM, Meindersma GW, Reith T, De Haan AB (2005) Air Gap Membrane Distillation: Modelling and Mass Transport Properties For Hollow Fibre Membranes. Separation and Purification Technology 43: 233-244.

10. Gil MAI, Payo MCG, Pineda CF (1999) Air Gap Membrane Distillation Of Sucrose Solutions. Journal of Membrane Science 155: 291-307.
11. Chouikh R, Bouguecha S, Dhahbi M (2005) Modelling Of A Modified Air Gap Distillation Membrane For The Desalination of Seawater. Desalination 181 257-265.

12. Mandiang Y, Sene M, Thiam A (2015) Mathematical Modeling And Simulation of Coupling Parameters Transfers of Steam In A Membrane-Type Solar Still Agmd. J Material Sci Eng 4: 1-13.

13. Morgado PI, Ricardo AA, Correiab IJ (2015) Asymmetric membranes as ideal wound dressings: An overview on production methods, structure, properties and performance relationship. Journal of Membrane Science 490: 139-151.

14. Lior N (2006) A Study of The State of The Art, Commercial Potential, And Prospects For Advancement of Desalination By Membrane Distillation. The Middle East Desalination Research Centre Muscat (Medrc), Sultanate of Oman.

15. Banat FA (1994) Membrane Distillation For Desalination And Removal of Volatile Organic Compounds From Water. Mcgill University, Canada.

16. Baoan Li, Kamalesh, Sirkar K (2005) Novel Membrane And Device For Vacuum Membrane Distillation-Based Desalination Process. Journal off Membrane Science 257: 60-75.

17. Ding Z, Ma R, Fane AG (2002) A New Model For Mass Transfer In Direct Contact Membrane Distillation. Desalination 151: 217-227. 